\title{
EDITORIAL
}

\section{Booster Dose of COVID 19 and Ethical Issues}

Prof. Dr Adeela Shahid

Doi: https://doi.org/10.53685/jshmdc.v2i2.82

COVID 19 is a pandemic of recent times and is a global health problem. In Pakistan, booster shots are recently made available only to those who can pay for the cost of the vaccine. The virus has no boundaries. It does not discriminate between rich and poor; both are at equal risk of having COVID. It is highly unethical to offer booster shots based on affordability when more than $70 \%$ population of Pakistan is still not vaccinated and belongs to a low socio-economic group. ${ }^{1}$

COVID-19 has cost the lives of many people worldwide; there was a lack of data to pre-vent and treat it. It reached Pakistan in February 2020; since then, many people have been affected. ${ }^{2}$ Many people died, including renowned healthcare workers, due to insufficient knowledge about this deadly virus. The only way to protect was to wear a mask and maintain social distance; no vaccine was available. It was an emergency condition in the world, so many countries started manufacturing vaccines and vaccinating people.

Despite having many types of vaccines manufactured, there is still a shortage of vaccines in the world. Phase-wise vaccination process started initially in many rich and developed countries to save the lives of people. According to World Health organization (WHO), at least $40 \%$ population of every country must be vaccinated by December 2021 and $70 \%$ by June $2022 .{ }^{3}$ According to the current statistics, more than $50 \%$ of the population is vaccinated in rich and developed countries, whereas in low-income countries like Uganda, only 1\% of the population has received the vaccine. Low-income countries have poor access to vaccines and have received only 13 million doses out of 4.5 billion distributed globally. ${ }^{4}$ In Pakistan, only $30.49 \%$ of the population has been vaccinated out of which $17.14 \%$ are fully vaccinated, and $13.35 \%$ have received only a single dose of COVID 19 vaccine. $^{1}$

A Utilitarian approach has been adopted at various levels since the pandemic emerged by health care organizations and the government. The purpose was to maximize the benefits and minimize the risk of harm. WHO proposed not to start COVID-19 booster shots unless at least $10 \%$ of population is fully vaccinated in every country. ${ }^{5}$ In these circumstances, when many countries are still waiting for the firstdose of COVID-19 vaccination, how fair and ethical is it to start administering booster doses? On the grounds of fairness, COVID-19 vaccination must be made available to poor and underprivileged countries as well before starting booster doses. ${ }^{6}$

The available vaccine is safe and effective against the prevalent variants of the COVID-19 virus. ${ }^{7}$ If vaccines are not made available to all countries and are instead stored for booster shots in limited countries, there are high chances that mutant variants of the virus will continue to develop. These newer variants may be more lethal and resistant to the vaccines already available. This calamity may affect the lives of millions around the globe.

Pakistan has deployed a fairly efficient and effective campaign of COVID-19 vaccination. Due to the limited availability, the government announced a stepwise vaccination program. The health care providers were among the first ones to receive the vaccines. The elderly and vulnerable were also offered a priority before the vaccination was offered to every citizen of Pakistan. Despite of massive 
campaigns, home-vaccination facilities and around the clock availability of vaccinations, the majority of the rural population is still unvaccinated. All government and non-government organizations have been directed to mandate vaccination to health care workers, employees, and students, without any exemptions. However, the availability of booster shots of Pfizer vaccine has been lately offered, at a cost fixed by the government, to all fully vaccinated individuals. This availability of booster based on affordability stands in contrast to the earlier applied approach based on distributive justice. Even an Egalitarian would argue against such a policy, as it restricts the availability of vaccines to not only the countries waiting for the first and second doses, but also to the individuals in Pakistan who cannot afford to spend money on an additional dose of vaccine. Pakistan is among the low-middle socio- economic countries' list of World Bank. A substantial amount of vaccines is made available through donations from affluent countries and organizations, apart from what is being purchased by the state. If Pakistan has enough vaccines to provide the first and second doses to the whole population, the rest may be directed towards the countries struggling to gain access to vaccines. This would be a fair demand from distributive justice perspective and a substantial contribution from a country that under- stands what global economic dynamics and politics mean for a developing country.

It is the need of the hour to think about health equity and justice in a pluralistic way and refrain from initiating booster shots for elite of a resource-poor country. This pandemic will never end if a maximum number of people are not vaccinated in each country. This is only possible if there is an equitable distribution of vaccines. Preventive medicine is not very popular in Pakistan. With the limited resources, an average Pakistani would spend on a medical treatment rather than on a preventive drug.

\section{References:}

1. Statistics and Research: Coronavirus (COVID-19) Vaccinations. Published online at OurWorldInData.org. Retrieved from: https://ourworldindata.org/covid-vaccinations.

2. Abid K, Bari YA, Younas M, Tahir Javaid S, Imran A. Progress of COVID-19 Epidemic in Pakistan. Asia Pac J Public Health. 2020; 32(4): 154-156

3. World Health Organization. Vaccine equity. Retrieved from: https://www.who.int/campaigns/vaccineequity.

4. The Lancet Infectious Diseases. COVID-19 vaccine equity and booster doses. Lancet Infect Dis. 2021; 21(9): 1193.

5. Jecker NS, Lederman Z. Three for me and none for you? An ethical argument for delaying COVID-19 boosters. J Med Ethics. 2021: medethics-2021-107824.

6. Schaefer GO, Leland RJ, Emanuel EJ. Making Vaccines Available to Other Countries before Offering Domestic Booster Vaccinations. JAMA. 2021; 326(10): 903-904

7. Bernal J.L., Andrews N., Gower C, Gallagher E, Simmons R, Thelwall S et al. Effectiveness of Covid-19 Vaccines against the B.1.617.2 (Delta) Variant. N Engl J Med. 2021; 385(7): 585-594.

How to cite this article: Shahid A. Booster dose of COVID 19 and ethical issues. JSHMDC. 2021; 2 (2): 54-55. doi:10.53685/jshmdc.v2i2.82

This article is published in JSHMDC under the terms of the Creative Commons Attribution License (http://creativecommons.org/licenses/ by/4.0), which permits unrestricted use, distribution, and reproduction in any medium, provided the original work is properly cited.

Corresponding Author:

Prof. Dr. Adeela Shahid

Chief Editor

Journal of Shalamar Medical \& Dental College, Lahore.

Email address: jsmdc@sihs.org.pk 